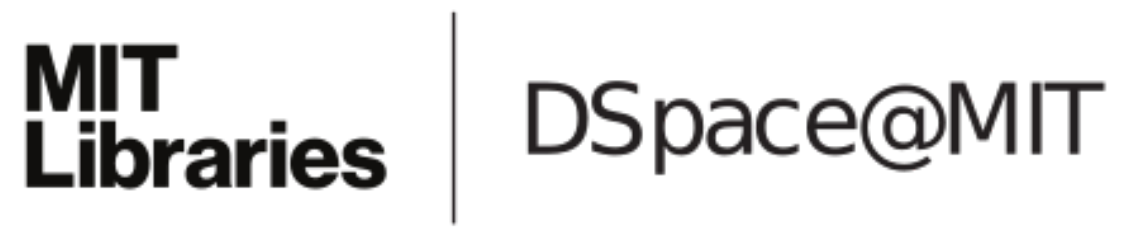

\author{
MIT Open Access Articles
}

Optimal Design of Grid-Connected PEV Charging
Systems With Integrated Distributed Resources

The MIT Faculty has made this article openly available. Please share how this access benefits you. Your story matters.

Citation: Gunter, Samantha J., Khurram K. Afridi, and David J. Perreault. "Optimal Design of Grid-Connected PEV Charging Systems With Integrated Distributed Resources." IEEE Transactions on Smart Grid 4, no. 2 (n.d.): 956-967.

As Published: http://dx.doi.org/10.1109/TSG.2012.2227514

Publisher: Institute of Electrical and Electronics Engineers (IEEE)

Persistent URL: http://hdl.handle.net/1721.1/86993

Version: Author's final manuscript: final author's manuscript post peer review, without publisher's formatting or copy editing

Terms of use: Creative Commons Attribution-Noncommercial-Share Alike 


\title{
Optimal Design of Grid-Connected PEV Charging Systems with Integrated Distributed Resources
}

\author{
Samantha J. Gunter, Student Member, IEEE, Khurram K. Afridi, Member, IEEE, \\ and David J. Perreault, Fellow, IEEE
}

\begin{abstract}
The penetration of plug-in electric vehicles and renewable distributed generation is expected to increase over the next few decades. Large scale unregulated deployment of either technology can have a detrimental impact on the electric grid. However, appropriate pairing of these technologies along with some storage could mitigate their individual negative impacts. This paper presents a framework and an optimization methodology for designing grid-connected systems that integrate plug-in electric vehicle chargers, distributed generation and storage. To demonstrate its usefulness, this methodology is applied to the design of optimal architectures for a residential charging case. It is shown that, given current costs, maximizing grid power usage minimizes system lifecycle cost. However, depending upon the location's solar irradiance patterns, architectures with solar photovoltaic generation can be more cost effective than architectures without. Additionally, Li-ion storage technology and micro wind turbines are not yet cost effective when compared to alternative solutions.
\end{abstract}

Index Terms - distributed power generation, electric vehicles, energy storage, linear programming, integer linear programming, power grids

\section{INTRODUCTION}

$\mathrm{G}$ ROWING concern for climate change and energy security has renewed interest in Plug-in Hybrid Electric Vehicles (PHEVs) and Electric Vehicles (EVs), collectively referred to as Plug-in Electric Vehicles (PEVs) [1], [2]. Some PHEVs and EVs have been released into the market, and although estimates vary, by 2020 roughly 2 million PEVs are expected to be on the road in the US, increasing to 14 million (about 5\% of the light duty vehicle fleet) by 2030 [3], [4]. However, penetration across the country is not expected to be uniform. Some west coast utilities expect PEV penetration of around 5\% in their service territories by as early as 2020 [5]. Such levels of penetration will require large scale deployment of residential and public chargers [6], [7]. In parallel to these developments, there is strong legislative effort to mandate, or incentivize, large scale integration of renewable energy resources, including renewable distributed generation (DG), into the electric grid. Twenty-nine U.S. states and the District

This work was supported by Siemens Corporation, Corporate Technology, Princeton, NJ, USA.

S. J. Gunter is with the Department of Electrical Engineering and Computer Science, Massachusetts Institute of Technology, Cambridge, MA 02139 USA, (phone: 617-258-8494; e-mail: sgunter@mit.edu).

K. K. Afridi is with the Department of Electrical Engineering and Computer Science, Massachusetts Institute of Technology, Cambridge, MA 02139 USA, (e-mail: afridi@mit.edu).

D. J. Perreault is with the Department of Electrical Engineering and Computer Science, Massachusetts Institute of Technology, Cambridge, MA 02139 USA, (e-mail: djperrea@mit.edu). of Columbia have established renewable portfolio standards that will drive the integration of substantial amounts of renewable energy into the grid by 2020 [8].

The potential impact of a large scale deployment of PEVs on the electric grid can be seen from the example of California shown in Fig. 1. As the penetration of PEVs increases, the additional annual energy demand due to these vehicles marginally increases the total annual electrical energy demand of the state (Fig. 1(a)). However, the peak power demand of the PEVs can significantly increase the total peak power demand of the state (Fig. 1(b)). Even small, but geographically concentrated, PEV penetrations could have substantial disruptive impact on local distribution systems, depending on the power rating of the chargers and the time of day when the vehicles are charged [9]-[11]. Also, integrating large levels of renewable DG into the grid is challenging as the variable and unpredictable nature of wind and solar make grid operations more difficult [12].

One potential way to mitigate the impact of PEV charging on the electric grid, while at the same time helping to achieve renewable portfolio standards, is to combine PEV charging with renewable DG and local storage into a single system. In fact, companies are beginning to explore this space as a commercially feasible endeavor [13]-[16]. However, it is unclear what architectural combination and control methodology makes the most practical sense in terms of cost and performance. In the past, methodologies have been developed to size stand-alone (i.e., non-grid connected) renewable DG and/or storage systems for non-PEV loads [17][20]. However, these methodologies do not address the design of grid-interfaced DG and/or storage systems, with their unique constraints and objective functions, to meet PEV charging requirements.

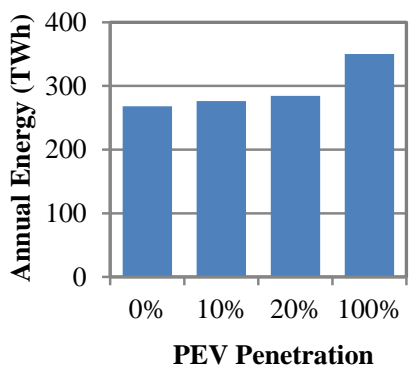

(a)

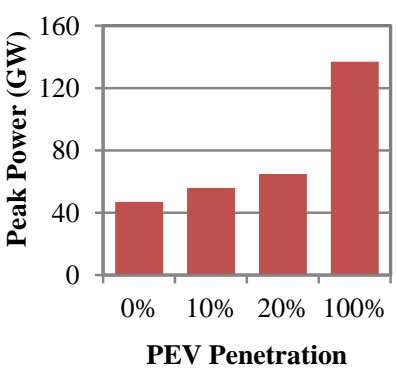

(b)
Fig. 1. Impact on California's (a) annual electrical energy demand, and (b) peak power demand for varying levels of PEV penetration out of the state's 30 million light duty vehicles. In (a), a 30 mile average daily commute at 4 miles/kWh vehicle efficiency is assumed. In (b), it is assumed that $50 \%$ of the PEVs are charging at the same time as the system peak at an average rate of 6 $\mathrm{kW}$. 
This paper presents a conceptual framework and a methodology for designing optimal architectures of gridinterfaced PEV chargers that integrate renewable DG and storage. This work represents an expansion on our earlier conference paper [21] and includes an additional mixed integer programming optimization approach as well as additional analyses on alternative renewable DG and storage technologies. The conceptual framework and the architectural space we consider are described in section II. Section III develops a system lifecycle cost model that is used to compare alternative designs. Section IV presents a methodology for determining an optimal architecture given certain design constraints, and formulates it using a linear programming approach, a search-based optimization approach, and a mixed integer programming approach. We apply these approaches to determine and explore optimal designs for a residential charging case in section V. Finally, section VI presents conclusions and directions for future work, and the appendix provides details on some of the cost and lifetime parameter values used in this paper.

\section{Framework For EVAluating Alternative PEV-GRID INTEGRATION ARCHITECTURES}

There are a number of different ways to configure and control a system consisting of PEV chargers, renewable distributed generation, energy storage and the electric grid. The system might not include storage and/or renewable DG. Alternatively, it might be a self-sufficient system with substantial renewable DG and storage, but no grid interface. If renewable DG, storage and grid interconnection are all present, their relative ratings can be quite different depending on how power flow is managed. For example, the system may or may not prefer to draw power from storage and/or renewable DG before drawing power from the grid; and it may impose different limits on the power that can be drawn from or delivered to the grid. Different designs can also be developed using alternate technologies for renewable DG (e.g., solar photovoltaic panel versus wind turbine) and storage (e.g., electrochemical battery versus flywheel).

Without a quantitative comparison of the alternative architectures in terms of system attributes of interest, it is not clear which architecture is the most appropriate. The system attributes that are of importance for a PEV charging system are cost, efficiency and reliability. We choose to compare alternative designs in terms of system lifecycle cost, which includes initial capital costs and operating costs (consisting of energy and maintenance costs). By including energy and maintenance costs in system lifecycle cost, we incorporate the impact of system efficiency and reliability on the results of our comparative analysis. In this paper we limit our analysis to charging systems with a single charger, a single renewable distributed generator, and a single storage unit, as shown in Fig. 2. However, the framework presented here is applicable to systems with multiple chargers, sources and storage units.

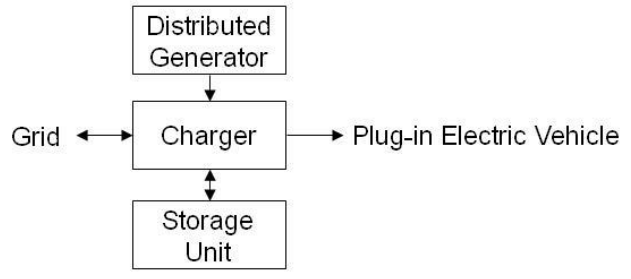

Fig. 2. PEV charging system with integrated renewable DG and storage.

\section{System Lifecycle Cost Model}

In this paper, alternative designs are compared in terms of lifecycle cost, $C$, which includes both the initial capital costs and the operating costs of the system:

$C=C_{D G}+C_{S}+C_{G}+C_{M}$,

where $C_{D G}$ and $C_{S}$ are the initial capital costs for the renewable DG and the storage unit, respectively, including any costs associated with their power electronic interface; $C_{G}$ is the cost associated with getting energy from the grid, and $C_{M}$ is the maintenance cost of the system. Collectively $C_{G}$ and $C_{M}$ represent the operating costs of the system over its lifetime. Note that while the system includes a PEV charger in addition to a renewable DG, a storage unit and a connection to the grid, the charger cost is not included in the system lifecycle cost model since it will have the same cost across the design space.

The initial capital costs of the renewable DG and storage unit are modeled as:

$C_{D G}=C_{D G, 0}+C_{D G}^{\prime} P_{D G, r}$,

$C_{S}=C_{S, 0}+C_{S}^{\prime} P_{S, r}+C_{S}^{\prime \prime} E_{S, r}$,

where $P_{D G, r}$, and $P_{S, r}$ are the power ratings of the renewable DG and storage unit, respectively, and $E_{S, r}$ is the energy storage capacity of the storage unit. $C_{D G, 0}$ and $C_{S, 0}$ are the fixed costs of the renewable DG and the storage unit, respectively, while $C^{\prime}{ }_{D G}$ is the variable cost of the renewable DG and $C^{\prime}{ }_{S}$ and $C{ }^{\prime \prime}$ are the variable costs of the storage unit with respect to power rating and energy rating, respectively. The cost associated with getting energy from the grid is modeled as:

$C_{G}=C_{G, 0} \frac{T_{l i f e, s y s}}{T_{b p}}+C_{G}^{\prime \prime} \frac{T_{l i f e, s y s}}{T_{b p}} E_{G, r}+C_{G}^{\prime} \frac{T_{l i f e, s y s}}{T_{b p}} P_{G, r}$,

where $E_{G, r}$ is the energy drawn from the grid over a billing period $T_{b p} ; P_{G, r}$ is the peak power drawn from the grid; and $T_{\text {life,sys }}$ is the lifetime of the system, i.e., the amount of time for which the charging system is expected to be used. The first two terms of (4) capture the consumption charge (consisting of distribution and energy charges) and the third term represents the demand charge. By modeling the maintenance cost as a cost associated primarily with the cost of replacing the renewable DG and the storage unit at the end of their respective lives, maintenance cost is given by:

$C_{M}=\operatorname{int}\left(\frac{T_{\text {life }, \text { sys }}}{T_{\text {life }, D G}}\right) \cdot C_{D G}+\operatorname{int}\left(\frac{T_{\text {life }, y y s}}{T_{\text {life }, S}}\right) \cdot C_{S}$,

where $T_{\text {life,DG }}$ and $T_{\text {life,S }}$ are the expected life of the renewable DG and storage unit, respectively, and int() is the floor function which rounds its argument down to the nearest integer. The cost and time duration parameters used in (2)-(5) are also defined in Table I. Additionally, Table I lists the 
TABLE I

COST AND TIME DURATION PARAMETERS USED IN THE SYSTEM LIFECYCLE COST MODEL

\begin{tabular}{|c|c|c|}
\hline Parameter & Description & Value \\
\hline$C_{D G, 0}$ & $\begin{array}{l}\text { Fixed capital cost of the renewable DG } \\
(\$)\end{array}$ & $\begin{array}{c}200 \text { (solar) } \\
3,750 \text { (wind) }\end{array}$ \\
\hline$C_{D G}^{\prime}$ & $\begin{array}{l}\text { Variable capital cost of the renewable } \\
\text { DG }(\$ / \mathrm{kW})\end{array}$ & $\begin{array}{l}4,400 \text { (solar) } \\
5,500 \text { (wind) }\end{array}$ \\
\hline$C_{S, 0}$ & Fixed capital cost of the storage unit $(\$)$ & $\begin{array}{l}110 \text { (lead-acid) } \\
80 \text { (Li-ion) }\end{array}$ \\
\hline$C_{S}^{\prime}$ & $\begin{array}{l}\text { Variable capital cost of the storage unit } \\
\text { depending on power rating }(\$ / \mathrm{kW})\end{array}$ & 200 \\
\hline$C^{\prime \prime} s$ & $\begin{array}{l}\text { Variable capital cost of the storage unit } \\
\text { depending on energy rating }(\$ / \mathrm{kWh})\end{array}$ & $\begin{array}{l}220 \text { (lead-acid) } \\
800 \text { (Li-ion) }\end{array}$ \\
\hline$C_{G, 0}$ & $\begin{array}{l}\text { Fixed distribution charge from the grid } \\
\text { per billing period }(\$)\end{array}$ & 9 \\
\hline$C_{G}^{\prime}$ & $\begin{array}{l}\text { Demand charge from the grid per billing } \\
\text { period }(\$ / \mathrm{kW})\end{array}$ & 0 \\
\hline$C^{\prime \prime}{ }_{G}$ & $\begin{array}{l}\text { Variable distribution and energy charge } \\
\text { from the grid }(\$ / \mathrm{kWh})\end{array}$ & 0.14 \\
\hline$T_{\text {life,sys }}$ & Expected life of the system (yr) & 20 \\
\hline$T_{\text {life. }, D G}$ & Expected life of the renewable DG (yr) & 25 \\
\hline$T_{\text {life,S }}$ & Expected life of the storage unit (yr) & $\begin{array}{l}6 \text { (lead-acid) } \\
12 \text { (Li-ion) }\end{array}$ \\
\hline$T_{b p}$ & Length of billing period (yr) & $1 / 12$ \\
\hline
\end{tabular}

example values for these parameters as used in this paper. Since demand charge is typically applicable only to industrial and large commercial customers, $C_{G}^{\prime}$ is assumed to be zero for our residential charging case.

\section{OPTIMIZATION METHODOLOGY}

In this paper an optimal architecture is one with the lowest system lifecycle cost, as modeled by (1). This cost depends on the ratings $P_{D G, r}, P_{S, r}, E_{S, r}, P_{G, r}$ and $E_{G, r}$. These ratings depend upon $P_{C}(t)$, the power drawn by the PEV charger as a function of time $t$, as well as the design constraints and the power flow control methodology.

Design constraints arise from the maximum power that can be drawn from and delivered to the grid, $P_{G, \max (p)}$ and $P_{G, \max (n)}$, respectively; limits on the maximum rating of the renewable DG, $P_{D G, \max }$; the maximum power and energy rating of the storage unit, $P_{S, \max }$ and $E_{S, \max }$, respectively; and the maximum and minimum state-of-charge allowed for the storage unit, $S O C_{\max }$ and $S O C_{\min }$, respectively. These constraints can be expressed as follows:

$-P_{G, \max (n)} \leq P_{G}(t) \leq P_{G, r} \leq P_{G, \max (p)}$,

$0 \leq P_{D G}(t) \leq P_{D G, r} \leq P_{D G, \max }$,

$-P_{S, \max } \leq-P_{S, r} \leq P_{S}(t) \leq P_{S, r} \leq P_{S, \max }$,

$E_{S, r} S O C_{\min } \leq E_{S}(t) \leq E_{S, r} S O C_{\max } \leq E_{S, \max } S O C_{\max }$,

where $P_{G}(t), P_{D G}(t)$, and $P_{S}(t)$ are the instantaneous powers delivered by the grid, the renewable DG, and the storage unit, respectively; and $E_{S}(t)$ is the instantaneous energy stored in the storage unit. The maximum power available from the grid could be limited due to the limited rating of a distribution transformer or a feeder line. The limits on the DG and storage
TABLE II

DESIGN CONSTRAINTS

\begin{tabular}{|c|c|c|}
\hline $\begin{array}{l}\text { Design } \\
\text { Constraint }\end{array}$ & Description & Value \\
\hline$P P_{G, \max (p)}$ & Maximum power allowed from the grid $(\mathrm{kW})$ & 5 \\
\hline$P_{G, \max (n)}$ & Maximum power allowed into the grid $(\mathrm{kW})$ & 0 \\
\hline$P_{\mathrm{DG}, \max }$ & $\begin{array}{l}\text { Maximum power rating of the renewable } \\
\text { distributed generation source }(\mathrm{kW})\end{array}$ & 10 \\
\hline$P_{S, \max }$ & Maximum power rating of the storage unit $(\mathrm{kW})$ & 10 \\
\hline$E_{S, \max }$ & Maximum energy capacity of the storage unit ( $\mathrm{kWh}$ ) & 100 \\
\hline $\mathrm{SOC}_{\max }$ & $\begin{array}{l}\text { Maximum fractional state-of-charge of the storage } \\
\text { unit (between } 0 \text { and } 1 \text { ) }\end{array}$ & 1 \\
\hline $\mathrm{SOC}_{\text {min }}$ & $\begin{array}{l}\text { Minimum fractional state-of-charge of the storage } \\
\text { unit (between } 0 \text { and } 1 \text { ) }\end{array}$ & 0.80 \\
\hline$T$ & $\begin{array}{l}\text { Time period over which the storage unit state-of- } \\
\text { charge is to be maintained }(\mathrm{yr})\end{array}$ & $1 / 365$ \\
\hline
\end{tabular}

could be due to space constraints. These design constraints along with their assumed values are summarized in Table II.

Additional constraints are imposed by physical laws and the connections between the components; including the following from energy conservation:

$P_{G}(t)+P_{D G}(t)+P_{S}(t)=P_{C}(t)$.

Also the instantaneous power from the DG satisfies:

$P_{D G}(t)=P_{D G, r} f_{D G}(t)$,

where $f_{D G}(t)$ is the normalized output power profile of the renewable distributed generation source, and varies between 0 and 1 due to variation in solar irradiation (or wind speed). Also the energy in the storage unit is related to the power drawn from it by:

$E_{S}(t)-E_{S}(t-\Delta t)=-\int_{t-\Delta t}^{t} \widetilde{P}_{S}\left(t^{\prime}\right) d t^{\prime}$,

where $\widetilde{P}_{S}(t)$ is given by:

$\tilde{P}_{S}(t)=\left\{\begin{array}{r}\frac{P_{S}(t)}{\sqrt{\eta}}, P_{S}(t)>0 \\ \sqrt{\eta} P_{S}(t), P_{S}(t) \leq 0,\end{array}\right.$

and incorporates the effect of the roundtrip efficiency of the storage unit, $\eta$. Other sources of loss are already incorporated into other aspects of the methodology. For instance, the inefficiency in the power electronics of the charger is incorporated into $P_{C}(t)$. Similarly, $f_{D G}(t)$ accounts for the conversion inefficiency from solar irradiance (or wind speed) to output power.

For steady state conditions, the system must return the storage unit to its original state-of-charge over some time period, $T$, i.e.,

$E_{S}(T)-E_{S}(0)=-\int_{0}^{T} \widetilde{P}_{S}\left(t^{\prime}\right) d t^{\prime}=0$.

For the analysis in this paper, $T$ is taken to be one day, unless otherwise specified. Finally, the energy and instantaneous power drawn from the grid are related as follows:

$E_{G, r}=\int_{0}^{T} P_{G}\left(t^{\prime}\right) d t^{\prime}$.

\section{A. Linear Programming Formulation}

In order to find the minimum lifecycle cost architecture we frame this problem first as a linear programming one. A linear programming problem can be expressed in conical form as:

$\min _{\boldsymbol{x}}\left(\boldsymbol{c}^{T} \boldsymbol{x}\right)$ subject to $\left\{\begin{array}{l}\boldsymbol{A} \cdot \boldsymbol{x} \leq \boldsymbol{b} \\ \boldsymbol{D} \cdot \boldsymbol{x}=\boldsymbol{g},\end{array}\right.$ 
where $\boldsymbol{c}^{T} \boldsymbol{x}$ is the cost function to be minimized, $\boldsymbol{c}$ is the cost vector and $\boldsymbol{x}$ is the feasible vector consisting of the decision variables [23]. In our case the cost function $\boldsymbol{c}^{T} \boldsymbol{x}$ is equal to the variable part of the system lifecycle cost expression developed in section III. The fixed cost components are not included in the optimization process but are appropriately added at the end. The vectors $\boldsymbol{b}$ and $\boldsymbol{g}$ and matrices $\boldsymbol{A}$ and $\boldsymbol{D}$ model the constraints of the system, in our case given by (6)-(15). Based on the system lifecycle cost model of (1), the decision variables in $\boldsymbol{x}$ could simply be $P_{G, r}, P_{D G, r}, P_{S, r}, E_{S, r}$, and $E_{G, r}$. However, since some of the constraints are on the instantaneous values of $P_{G}(t), P_{D G}(t), P_{S}(t)$ and $E_{S}(t)$, these must also be represented in $\boldsymbol{x}$. Hence, $\boldsymbol{x}$ can be expressed as:

$\boldsymbol{x}=\left[\boldsymbol{p}_{G} P_{G, r} \boldsymbol{p}_{D G} P_{D G, r} \boldsymbol{p}_{S} P_{S, r} \boldsymbol{e}_{S} E_{S, r} E_{G, r}\right]^{\mathrm{T}}$,

where $\boldsymbol{p}_{G}, \boldsymbol{p}_{D G}$, and $\boldsymbol{p}_{S}$ are vectors representing the discrete time output power profiles of the grid, renewable DG and storage unit, respectively; and $\boldsymbol{e}_{S}$ represents the discrete time energy stored in the storage unit, i.e.:

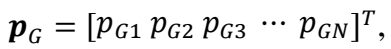

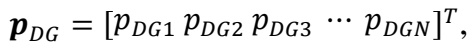

$\boldsymbol{p}_{S}=\left[\begin{array}{llll}p_{S 1} & p_{S 2} p_{S 3} & \cdots & p_{S N}\end{array}\right]^{T}$,

$\boldsymbol{e}_{S}=\left[\begin{array}{lllll}e_{S 1} & e_{S 2} & e_{S 3} & \cdots & e_{S N}\end{array}\right]^{T}$.

These four vectors are of length $N$, where $N$ equals the time period, $T$, divided by the desired time step, $\Delta t$. Hence, $\boldsymbol{x}$ is of length $4 N+5$. To match the continuously variable part of (1) to $c^{T} \boldsymbol{x}, \boldsymbol{c}$ is expressed as:

$$
\boldsymbol{c}=\left[\begin{array}{c}
\mathbf{0} \\
C_{G}^{\prime} \cdot \frac{T_{\text {life,sys }}}{T_{b p}} \\
\mathbf{0} \\
C_{D G}^{\prime} \cdot \operatorname{int}\left(1+\frac{T_{\text {life }, \text { sys }}}{T_{\text {life }, D G}}\right) \\
\mathbf{0} \\
C_{S}^{\prime} \cdot \operatorname{int}\left(1+\frac{T_{\text {life }, \text { sys }}}{T_{\text {life }, S}}\right) \\
\mathbf{0} \\
\mathrm{C}_{\mathrm{S}}^{\prime \prime} \cdot \operatorname{int}\left(1+\frac{T_{\text {life }, \text { sys }}}{T_{\text {life }, S}}\right) \\
\mathrm{C}_{\mathrm{G}}^{\prime \prime} \cdot \frac{T_{\text {life,sys }}}{T_{b p}}
\end{array}\right]
$$

where each zero vector is of length $N$.

The constraints given by (6)-(9) are modeled by $\boldsymbol{A} \cdot \boldsymbol{x} \leq \boldsymbol{b}$ where $\boldsymbol{b}$ (of length $8 N+4$ ) has the form:

$\boldsymbol{b}=\left[\begin{array}{llll}\boldsymbol{b}_{1} & \boldsymbol{b}_{2} & \boldsymbol{b}_{3} & \boldsymbol{b}_{4}\end{array}\right]^{\mathrm{T}}$,

with the following sub-vectors, each of length $2 N+1$ :

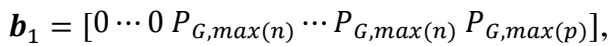

$\boldsymbol{b}_{2}=\left[\begin{array}{lllllll}0 & \cdots & 0 & 0 & \cdots & 0 & P_{D G, \max }\end{array}\right]$,

$\boldsymbol{b}_{3}=\left[\begin{array}{lllllll}0 & \cdots & 0 & 0 & \cdots & 0 & P_{S, \max }\end{array}\right]$,

$\boldsymbol{b}_{4}=\left[\begin{array}{lllllll}0 & \cdots & 0 & 0 & \cdots & 0 & E_{S, \max }\end{array}\right]$.

$\boldsymbol{A}$ has $4 N+5$ columns and $8 N+4$ rows and is of the form:

$\boldsymbol{A}=\left[\begin{array}{ccccc}\boldsymbol{A}_{1} & \mathbf{0} & \mathbf{0} & \mathbf{0} & \mathbf{0} \\ \mathbf{0} & \boldsymbol{A}_{2} & \mathbf{0} & \mathbf{0} & \mathbf{0} \\ \mathbf{0} & \mathbf{0} & \boldsymbol{A}_{3} & \mathbf{0} & \mathbf{0} \\ \mathbf{0} & \mathbf{0} & \mathbf{0} & \boldsymbol{A}_{4} & \mathbf{0}\end{array}\right]$,

and the sub-matrices $\boldsymbol{A}_{1}, \boldsymbol{A}_{2}, \boldsymbol{A}_{3}$, and $\boldsymbol{A}_{4}$ each having $2 N+1$ rows and $N+1$ columns are given by:

$$
\begin{aligned}
\boldsymbol{A}_{1} & =\boldsymbol{A}_{2}=\left[\begin{array}{ccccccc}
1 & 0 & 0 & \cdots & 0 & 0 & -1 \\
0 & 1 & 0 & \cdots & 0 & 0 & -1 \\
\vdots & & & \vdots & & & \vdots \\
0 & 0 & 0 & \cdots & 0 & 1 & -1 \\
-1 & 0 & 0 & \cdots & 0 & 0 & 0 \\
0 & -1 & 0 & \cdots & 0 & 0 & 0 \\
\vdots & & & \vdots & & & \vdots \\
0 & 0 & 0 & \cdots & 0 & -1 & 0 \\
0 & 0 & 0 & \cdots & 0 & 0 & 1
\end{array}\right], \\
\boldsymbol{A}_{3} & =\left[\begin{array}{cccccccc}
1 & 0 & 0 & \cdots & 0 & 0 & -1 \\
0 & 1 & 0 & \cdots & 0 & 0 & -1 \\
\vdots & & & \vdots & & & \vdots \\
0 & 0 & 0 & \cdots & 0 & 1 & -1 \\
-1 & 0 & 0 & \cdots & 0 & 0 & -1 \\
0 & -1 & 0 & \cdots & 0 & 0 & -1 \\
\vdots & & & \vdots & & & \vdots \\
0 & 0 & 0 & \cdots & 0 & -1 & -1 \\
0 & 0 & 0 & \cdots & 0 & 0 & 1
\end{array}\right], \\
\boldsymbol{A}_{4} & =\left[\begin{array}{cccccccc}
1 & 0 & 0 & \cdots & 0 & 0 & -S O C_{\max } \\
0 & 1 & 0 & \cdots & 0 & 0 & -S O C_{\max } \\
\vdots & & & \vdots & & & \vdots \\
0 & 0 & 0 & \cdots & 0 & 1 & -S O C_{\max } \\
-1 & 0 & 0 & \cdots & 0 & 0 & S O C_{\min } \\
0 & -1 & 0 & \cdots & 0 & 0 & S O C_{\min } \\
\vdots & & & \vdots & & & \vdots \\
0 & 0 & 0 & \cdots & 0 & -1 & S O C_{\min } \\
0 & 0 & 0 & \cdots & 0 & 0 & 1
\end{array}\right] .
\end{aligned}
$$

In the above formulation $\boldsymbol{A}_{\boldsymbol{I}}$ and $\boldsymbol{b}_{\boldsymbol{1}}$ model the constraints on power drawn from the grid given by (6); $\boldsymbol{A}_{2}$ and $\boldsymbol{b}_{2}$ model the constraints on power from the renewable DG given by (7); $\boldsymbol{A}_{3}$ and $\boldsymbol{b}_{3}$ model the constraints on power from the storage unit given by (8); and $\boldsymbol{A}_{4}$ and $\boldsymbol{b}_{\boldsymbol{4}}$ model the constraints on the stored energy given by (9).

The constraints (10)-(15) are modeled by $\boldsymbol{D} \cdot \boldsymbol{x}=\boldsymbol{g}$, where $\boldsymbol{g}$ is of length $3 N+1$ and is represented as:

$\boldsymbol{g}=\left[\begin{array}{llll}\boldsymbol{p}_{C} & 0 & \cdots & 0\end{array}\right]^{\mathrm{T}}$.

Here $\boldsymbol{p}_{\mathbf{C}}$, of length $N$, is the discrete time representation of the power drawn by the charger:

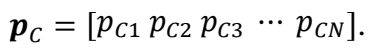

$\boldsymbol{D}$ takes the following form:

$\boldsymbol{D}=\left[\begin{array}{ccccc}\boldsymbol{D}_{1} & \boldsymbol{D}_{1} & \boldsymbol{D}_{1} & \mathbf{0} & \mathbf{0} \\ \mathbf{0} & \boldsymbol{D}_{2} & \mathbf{0} & \mathbf{0} & \mathbf{0} \\ \mathbf{0} & \mathbf{0} & \boldsymbol{D}_{3} & \boldsymbol{D}_{4} & \mathbf{0} \\ \boldsymbol{d}_{5} & \mathbf{0} & \mathbf{0} & \mathbf{0} & -1\end{array}\right]$,

where the row vector $\boldsymbol{d}_{5}$ has $N+1$ columns and is given by:

$\boldsymbol{d}_{5}=[\Delta t \cdots \Delta t 0]$.

The sub-matrices $\boldsymbol{D}_{1}, \boldsymbol{D}_{2}, \boldsymbol{D}_{3}$, and $\boldsymbol{D}_{4}$, each having $N$ rows and $N+1$ columns, are given by:

$\begin{aligned} \boldsymbol{D}_{1} & =\left[\begin{array}{ccccccc}1 & 0 & 0 & \cdots & 0 & 0 & 0 \\ 0 & 1 & 0 & \cdots & 0 & 0 & 0 \\ \vdots & & & \vdots & & & \vdots \\ 0 & 0 & 0 & \cdots & 0 & 1 & 0\end{array}\right], \\ \boldsymbol{D}_{2} & =\left[\begin{array}{ccccccc}1 & 0 & 0 & \cdots & 0 & 0 & -f_{D G 1} \\ 0 & 1 & 0 & \cdots & 0 & 0 & -f_{D G 2} \\ \vdots & & & \vdots & & & \vdots \\ 0 & 0 & 0 & \cdots & 0 & 1 & -f_{D G N}\end{array}\right],\end{aligned}$ 
$\boldsymbol{D}_{3}=\left[\begin{array}{ccccccc}d_{11} & 0 & 0 & \cdots & 0 & 0 & 0 \\ 0 & d_{22} & 0 & \cdots & 0 & 0 & 0 \\ \vdots & & & \vdots & & & \vdots \\ 0 & 0 & 0 & \cdots & 0 & d_{N N} & 0\end{array}\right]$,

$\boldsymbol{D}_{4}=\left[\begin{array}{ccccccc}1 & 0 & 0 & \cdots & 0 & -1 & 0 \\ -1 & 1 & 0 & \cdots & 0 & 0 & 0 \\ \vdots & & & \vdots & & & \vdots \\ 0 & 0 & 0 & \cdots & -1 & 1 & 0\end{array}\right]$.

In (37), $f_{D G n}$ is the $\mathrm{n}^{\text {th }}$ element of $\boldsymbol{f}_{D G}$ (the discrete time version of $\left.f_{D G}(t)\right)$ :

$\boldsymbol{f}_{D G}=\left[\begin{array}{lllll}f_{D G 1} & f_{D G 2} & f_{D G 3} & \cdots & f_{D G N}\end{array}\right]^{T}$,

and in (38), $d_{n n}$ is given by:

$d_{n n}=\left\{\begin{array}{l}\sqrt{\eta} \Delta t, p_{C n} \leq 0 \\ \frac{1}{\sqrt{\eta}} \Delta t, p_{C n}>0,\end{array}\right.$

where we have assumed that the storage unit will not charge when the PEV charger is drawing power. In the above formulation $\boldsymbol{D}_{1}$ models the power balance constraint given by (10); $\boldsymbol{D}_{2}$ models the constraint on the instantaneous output power of the renewable DG given by (11); $\boldsymbol{D}_{3}$ and $\boldsymbol{D}_{4}$ collectively model the constraint on the instantaneous energy of the storage given by (12) and (14); and $\boldsymbol{d}_{5}$ models the energy drawn from the grid given by (15). This linear programming formulation is implemented in MATLAB.

\section{B. Search-Based Formulation}

To validate the results of the linear programming based optimization, and to investigate its design decisions, we have also developed a search-based optimization technique and implemented it in MATLAB. In this approach we size the renewable DG and storage unit for different design options and then compare these alternate designs in terms of their system lifecycle cost. To keep the search manageable we search across only a limited set of feasible designs. Hence, the success of this approach requires ensuring that the feasible designs considered include the optimal design. For the cases we consider in section $\mathrm{V}$, a feasible design must include storage, however, designs with and without DG are feasible.

The sizing algorithm depends upon whether or not DG is present. In architectures where a distributed generator is present, the algorithm takes an iterative approach. It starts with $P_{D G, r}$ equal to zero, computes the change in the state-ofcharge of the storage unit over the time period $T$ using (14), and keeps increasing the size of the DG until the change in the state-of-charge is zero. For this state-of-charge calculation $P_{S}(t)$ must be known and is computed using $(10)$, where $P_{D G}(t)$ is given by (11) and $P_{G}(t)$ is calculated from:

$P_{G}(t)=\min \left(P_{G, r}, \max \left(-P_{G, \max (n)}, P_{C}(t)-P_{D G}(t)\right)\right)$.

In developing (42) we have assumed that the power flow in our system is controlled in such a way that the charger first takes power from the renewable DG. When the renewable DG cannot meet the full power needs of the charger, the remaining power is first drawn from the grid. Only when the grid power hits its limit do we draw power from the storage unit. This power flow control assumption limits the architectures that we search across. However, since this control methodology minimizes the amount of storage needed, this approach will search through the space of potential least cost architectures that contain DG. We parameterize this sizing algorithm in terms of $P_{G, r}$, and generate multiple designs by sweeping across different values of $P_{G, r}$ in the range of 0 through $P_{G, \max (p) \text {. }}$

In architectures where no DG is present a slightly different approach is followed. This is necessary because now instead of the DG, the grid will have to charge the storage unit (it will do so when the electric vehicle is not charging). To incorporate this change in control methodology, we first calculate the energy that has to be supplied to the charger from the storage unit when the electric vehicle is charging:

$E_{S 2 C}=\int_{0}^{\mathrm{T}} P_{S 2 C}(t) d t$,

where $P_{S 2 C}(t)$ is the power supplied to the charger from the storage unit:

$P_{S 2 C}(t)=\left\{\begin{array}{r}0, P_{C}(t) \leq 0 \\ P_{C}(t)-P_{G, r}, P_{C}(t)>0 .\end{array}\right.$

The energy taken from the storage unit must be returned to it from the grid when the electric vehicle is not charging. Hence, the output power flowing from the storage unit at all times can be expressed as:

$P_{S}(t)=\left\{\begin{array}{c}-\frac{1}{\eta} \cdot \frac{E_{S 2 C}}{T_{C, o f f}}, P_{C}(t) \leq 0 \\ P_{C}(t)-P_{G, r}, P_{C}(t)>0 .\end{array}\right.$

Here we have assumed that our system controller recharges the battery evenly across the time period when the PEV is not charging, denoted as $T_{C, \text { off }}$. Now that the output power profile of the storage unit is known, the instantaneous power drawn from the grid is:

$P_{G}(t)=\min \left(P_{G, r}, \max \left(-P_{G, \max (n)}, P_{C}(t)-P_{S}(t)\right)\right)$.

For either case (with or without DG), once $P_{G}(t), P_{D G}(t)$ and $P_{S}(t)$ that satisfy the state-of-charge requirement have been determined, the sizing algorithm proceeds to calculate the remaining three system ratings needed for system lifecycle cost calculation. Of these $E_{G, r}$ is calculated using (15); and the other two are calculated using:

$P_{S, r}=\max _{\mathrm{t}}\left(\left|P_{S}(t)\right|\right)$,

$E_{S, r}=\frac{\max _{\mathrm{t}}\left(\Delta \mathrm{E}_{\mathrm{s}}(t)\right)-\min _{\mathrm{t}}\left(\Delta \mathrm{E}_{\mathrm{s}}(t)\right)}{S O C_{\text {max }}-S O C_{\min }}$,

where $\max _{\mathrm{t}}()$ and $\min _{\mathrm{t}}()$ return the maximum and minimum value of their argument over $0 \leq t \leq T$, and $\Delta E_{s}(t)$ is given by:

$\Delta E_{S}(t) \equiv E_{S}(t)-E_{S}(0)=-\int_{0}^{t} \widetilde{P_{S}}\left(t^{\prime}\right) d t^{\prime}$.

Once the system has been designed the algorithm also checks to make sure that the following design constraints are satisfied:

$P_{D G, r} \leq P_{D G, \max }$

$P_{S, r} \leq P_{S, \max }$

$E_{S, r} \leq E_{S, \max }$.

If these are not satisfied the design is discarded. 


\section{Mixed Integer Programming Formulation}

To validate both of the above described approaches, we also formulated the minimization of the system lifecycle cost model developed in section III (which is an affine function), subject to the design constraints given by (6)-(15) as a mixed integer programming problem in ILOG CPLEX. For the mixed integer programming formulation, the four components of the system lifecycle cost model are reframed as follows:

$$
\begin{aligned}
C_{D G}= & C_{D G, 0} b_{D G}+C_{D G}^{\prime} P_{D G, r}, \\
C_{S}= & C_{S, 0} b_{S}+C_{S}^{\prime} P_{S, r}+C_{S}^{\prime \prime} E_{S, r}, \\
C_{G}= & \frac{T_{\text {life }, \text { sys }}}{T_{b p}}\left(C_{G, 0} b_{G}+C_{G}^{\prime \prime} E_{G, r}+C_{G}^{\prime} P_{G, r}\right), \\
C_{M}= & \operatorname{int}\left(\frac{T_{\text {life }, \text { sys }}}{T_{\text {life }, D G}}\right) \cdot\left(C_{D G, 0} b_{D G}+C_{D G}^{\prime} P_{D G, r}\right) \\
& +\operatorname{int}\left(\frac{T_{\text {life }, \text { sys }}}{T_{\text {life }, S}}\right) \cdot\left(C_{S, 0} b_{S}+C_{S}^{\prime} P_{S, r}+C_{S}^{\prime \prime} E_{S, r}\right) .
\end{aligned}
$$

Here $b_{\mathrm{DG}}, b_{\mathrm{S}}$, and $b_{\mathrm{G}}$ are binary variables. Their values are determined as follows:

$$
\begin{gathered}
b_{D G}= \begin{cases}0, & P_{D G, r}=0 \\
1, & P_{D G, r}>0,\end{cases} \\
b_{G}= \begin{cases}0, & P_{G, r}=0 \\
1, & P_{G, r}>0,\end{cases} \\
b_{S}= \begin{cases}0, & P_{S, r}=0 \\
1, & P_{S, r}>0 .\end{cases}
\end{gathered}
$$

Unlike the linear programming formulation, this allows us to consider the full system lifecycle model, including the constant terms, in the optimization.

\section{Comparison Between Formulations}

Each formulation has strengths and weaknesses. The searchbased approach is heuristic in nature and relies on the accuracy of our intuition about how the charging system works to yield the optimal design. The linear programming approach is mathematically rigorous, but is limited to systems with a linear objective function and constraints. The mixed integer programming approach is the most accurate formulation for the affine system lifecycle cost model discussed in this paper, but it is computationally more demanding than linear programming.

\section{Residential Charging CASE Study}

Thus far, an optimization methodology and three different formulations for implementing it have been presented. To validate the methodology, all three formulations are applied to a case study and the results are compared. The specific case analyzed using the optimization methodology is that of a representative residential Level II charging system. We assume that an electric vehicle with a $30 \mathrm{kWh}$ battery has to be fully recharged every evening from $20 \%$ state-of-charge. We also assume that the owner desires to charge the vehicle within 4 hours using a $6 \mathrm{~kW}$ charger starting at $7 \mathrm{pm}$ each day. This charging rate is consistent with standardized Level II chargers [6] and the charging time follows documented user behavior [24]. The case study further assumes that the neighborhood in which the house is located is serviced by a 25
$\mathrm{kVA}$ transformer and the typical load between $7 \mathrm{pm}$ and 11 $\mathrm{pm}$ of all the houses serviced by this transformer is $20 \mathrm{~kW}$, excluding the charging needs of the EV. This situation is quite reasonable given the loading seen on existing transformers [25]. Hence, the maximum power that can be drawn from the grid, $P_{G, \max (p)}$, without overloading the transformer is $5 \mathrm{~kW}$.

Clearly the system requirements cannot be met with a gridonly charging solution, as the charging rate $(6 \mathrm{~kW})$ exceeds the maximum allowable power draw from the grid $(5 \mathrm{~kW})$. Hence, a storage unit and/or renewable DG will be needed. The storage unit will be necessary with solar photovoltaic (PV) distributed generation as the solar panel cannot produce any power in the late evening hours when the vehicle is to be charged. In this paper we first consider designs with a solar PV distributed generator and a lead-acid electrochemical storage unit for two locations in the US: Eugene, Oregon and Los Angeles, California. We then consider designs with a micro wind turbine generator instead of solar PV for Los Angeles, California and Boulder, Colorado. Lastly, we analyze the impact on system lifecycle cost when the lead-acid battery is replaced by a Li-ion battery, when the PEV charging time is shifted, and when the variable cost of solar decreases.

For each location, an optimal design is determined based on a 20 -year system lifecycle cost using the linear programming formulation of section IV. The parameters and design constraints given in Table I and II are used and the round-trip efficiency of storage, $\eta$, is assumed to be $85 \%$. The results are validated using the search-based optimization and mixed integer programming based approaches. For the residential case, the linear programming approach is an order of magnitude faster than the search-based one $(3.88 \mathrm{~s}$ versus $41.14 \mathrm{~s}$ ) and 2.5 times faster than the mixed integer programming approach (3.88 s versus $10.45 \mathrm{~s})$. However, large memory resources are required to store matrices $\boldsymbol{A}$ and $D$, which become larger when the time step is made smaller compared to the time period $T$. At one minute resolution, it takes around four times more memory to run the linear programming implementation than it does to run the searchbased and mixed integer programming approaches ( 900 MB versus $\sim 250 \mathrm{MB}$ and $\sim 200 \mathrm{MB}$ ) on an Intel Dual Core, 2.67 $\mathrm{GHz}$ processor.

\section{A. Dependence on Solar Irradiation Profile}

An important parameter in our optimization methodology is the normalized output power profile of the distributed generation source, $f_{D G}$. Fig. 3 shows the variation in $f_{D G}$ over a day for high $\left(95^{\text {th }}\right.$ percentile $)$, median $\left(50^{\text {th }}\right.$ percentile $)$ and low $\left(5^{\text {th }}\right.$ percentile) output power profile cases using 5-minute interval irradiation data for Eugene, OR from 1995-2011 [26].

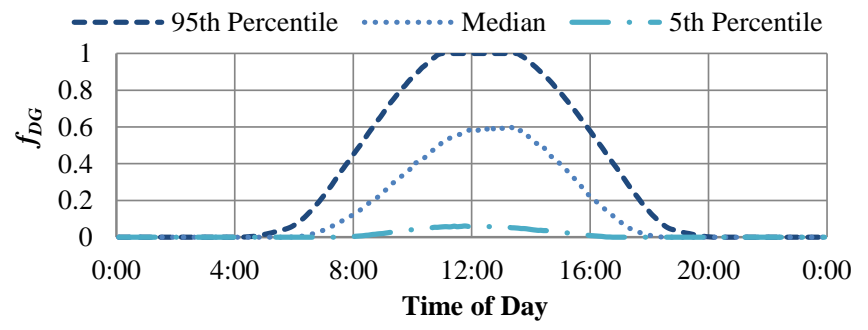

Fig. 3. Normalized output power profile for solar photovoltaic generation at different levels of solar insolation. Insolation data for Eugene, OR from 1995 to 2011 [26]. 
The $95^{\text {th }}, 50^{\text {th }}$, and $5^{\text {th }}$ percentile $f_{D G}$ represent profiles that are above $95 \%, 50 \%$ and $5 \%$ of the data at a particular time of the day, respectively. The $95^{\text {th }}$ percentile $f_{D G}$ has a flat top because typical solar panel name-plate ratings are based on $1000 \mathrm{~W} / \mathrm{m}^{2}$ solar irradiation, while the $95^{\text {th }}$ percentile irradiation for Eugene goes above $1000 \mathrm{~W} / \mathrm{m}^{2}$ around 12 noon.

When the $95^{\text {th }}$ percentile $f_{D G}$ is used in the design of the charging system, the lowest lifecycle cost solution is one that includes a solar PV DG. The ratings of the individual components for this optimal design are given in Table III. The power flow and stored energy as a function of time for this optimal design are shown in Fig. 4(a). As expected, the stored energy returns to its initial value after 24 hours. Note that the optimal design uses the maximum available power from the grid when the vehicle is charging. This is expected since without a high demand charge, the grid is the lowest cost alternative for peak power. However, notice that the battery is charged using the DG instead of the grid. This is because the cost of solar PV is lower than the cost of energy from the grid over the 20-year system life.

TABLE III

OPTIMAL DESIGN RATINGS AND LIFECYCLE COSTS

\begin{tabular}{crrrrrr}
\hline \hline $\begin{array}{c}f_{D G} \\
\text { (percentile) }\end{array}$ & $\begin{array}{c}\mathrm{P}_{\mathrm{DG}, \mathrm{r}} \\
(\mathrm{kW})\end{array}$ & $\begin{array}{c}\mathrm{P}_{\mathrm{S}, \mathrm{r}} \\
(\mathrm{kW})\end{array}$ & $\begin{array}{c}\mathrm{P}_{\mathrm{G}, \mathrm{r}} \\
(\mathrm{kW})\end{array}$ & $\begin{array}{c}\mathrm{E}_{\mathrm{S}, \mathrm{r}} \\
(\mathrm{kWh})\end{array}$ & $\begin{array}{c}\mathrm{E}_{\mathrm{G}, \mathrm{r}} \\
(\mathrm{kWh})\end{array}$ & $\begin{array}{c}\mathrm{C} \\
(\$)\end{array}$ \\
\hline $95^{\text {th }}$ & 0.578 & 1 & 5 & 21.63 & 600 & 43,687 \\
$50^{\text {th }}$ & 0 & 1 & 5 & 21.68 & 741 & 45,891 \\
\hline \hline
\end{tabular}
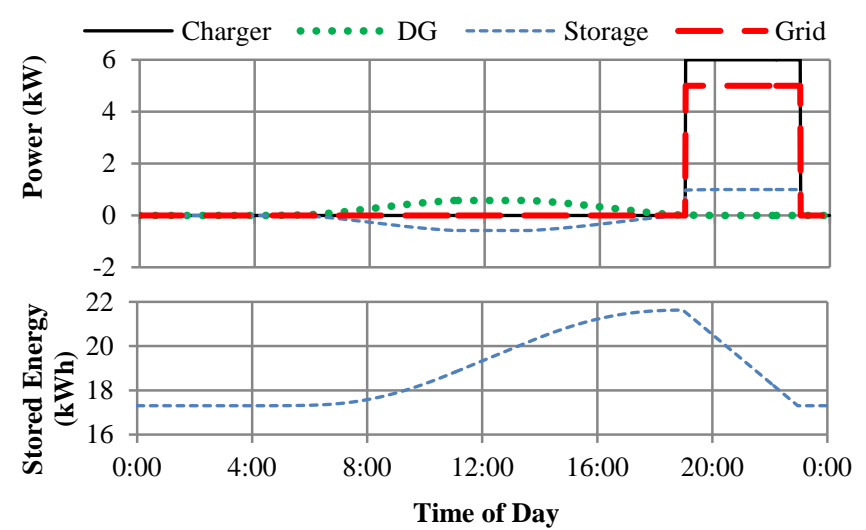

(a)
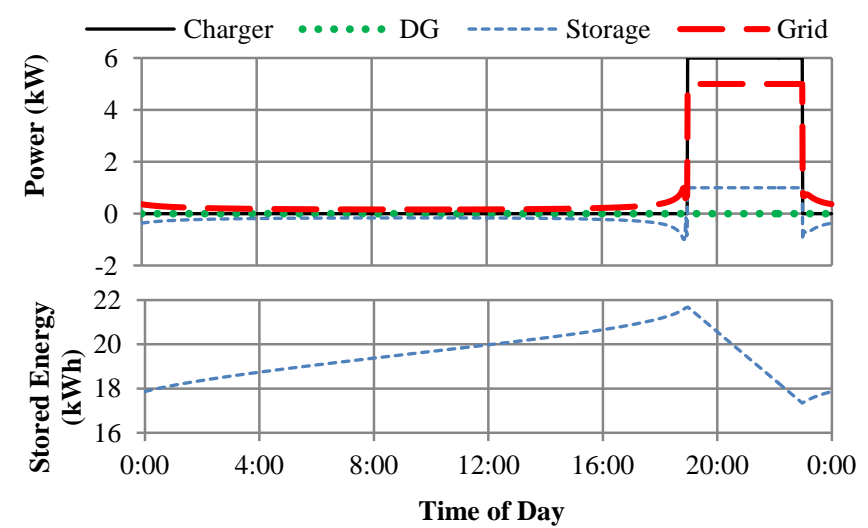

(b)

Fig. 4. Power and energy profile for the optimal design of a residential EV charger with integrated solar photovoltaic generation and lead-acid battery, assuming (a) $95^{\text {th }}$ percentile and (b) median $\left(50^{\text {th }}\right.$ percentile) normalized output power profiles of Fig. 3.
When the median $f_{D G}$ is used in the design of the system, the lowest lifecycle cost solution is one that does not include a solar PV generator (see Table III). Instead the system relies on the grid to charge the battery for use when the vehicle is charging. This is because the lower normalized energy under the median $f_{D G}$ profile necessitates the need for a DG with roughly twice the rating compared to the DG needed for the $95^{\text {th }}$ percentile case. As a result, the cost of the DG is more than the cost of energy from the grid over the system life. The power flow and stored energy for this optimal design are shown in Fig. 4(b).

Clearly whether or not the DG based design is optimal depends on the solar irradiance profile. Fig. 5 presents the system lifecycle cost of the optimal design for different $f_{D G}$ profiles, ranging from the $5^{\text {th }}$ percentile to the $95^{\text {th }}$ percentile using Eugene, OR data. Up to the $50^{\text {th }}$ percentile the optimal design does not utilize the solar PV. However, once the solar irradiance is at or above the $53^{\text {rd }}$ percentile level, corresponding to a peak, midday irradiance of about 720 $\mathrm{W} / \mathrm{m}^{2}$, the design with solar PV is optimal. The median irradiance of Eugene is just below this threshold. Fig. 5 also displays that the linear programming, search-based, and mixed integer programming approaches identify the same optimal design.

\section{B. Optimization Across Non-identical Days}

Our analysis so far has implicitly assumed that all days have identical solar irradiation profiles. In order to investigate optimal designs for systems operating over dissimilar irradiance days, we create an $f_{D G}$ profile that models the variation in irradiance over a full year using an equivalent 6day-length irradiance profile. Each day's irradiance represents the median of two consecutive months. The first day represents the median profile for a day in January or February followed by a day that represents the median profile for a day in March or April. In this way, we can represent a full year's seasonal fluctuation through a 6-day equivalent model. This 6day $f_{D G}$ profile is shown for Eugene, OR and Los Angeles, CA in Fig. 6. The Los Angeles $f_{D G}$ profile is based on 1-minute interval irradiation data from 2010-2011 [27]. Notice that Eugene has lower average irradiation than Los Angeles.

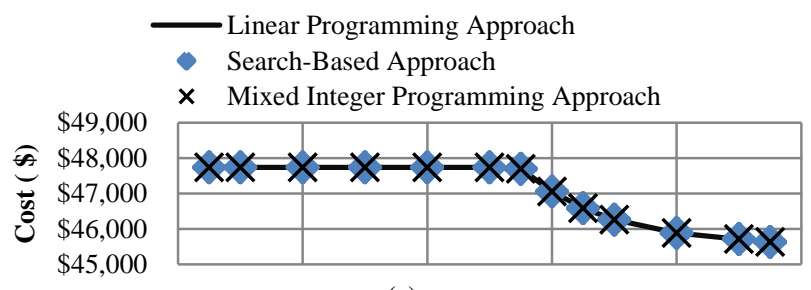

(a)

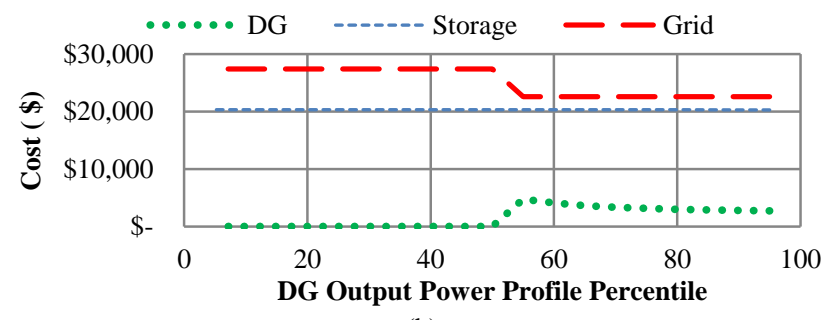

(b)

Fig. 5. (a) System lifecycle cost and (b) its components as the solar photovoltaic generation source's normalized output power profile is varied from the $5^{\text {th }}$ percentile to the $95^{\text {th }}$ percentile using Eugene, OR data [26]. 


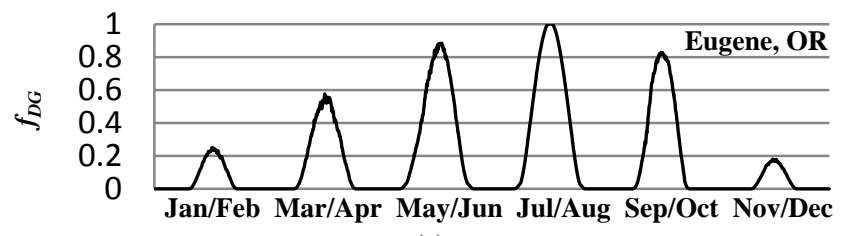

(a)

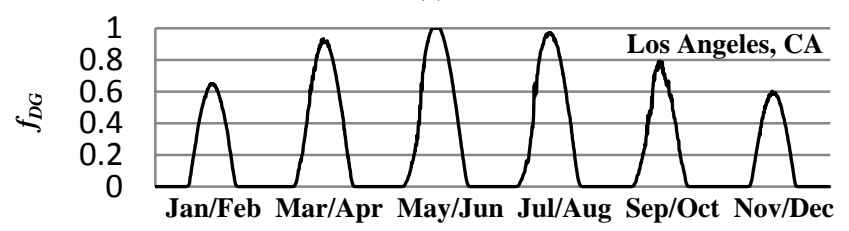

(b)

Fig. 6. Two-month median normalized output power profiles across a year for (a) Eugene, OR and (b) Los Angeles, CA [26], [27].

When the $f_{D G}$ profiles of Fig. 6 are used in the design of the charging system with $T$ (time after which the storage unit must be returned to its original state-of-charge) set to 6 days, the optimal design for Eugene does not have a solar photovoltaic generation source, while the optimal design for Los Angeles does. The power flow and stored energy waveforms for optimal designs in Eugene and Los Angeles are shown in Fig. 7(a) and 7(b), respectively. As before, the lowest cost design uses the maximum available power from the grid when the vehicle is charging. Notice also that the optimal design returns the stored energy to its initial level after each day, even though the imposed constraint is over 6 days. This is because the battery cost is a very large fraction of the total lifecycle cost and by bringing the battery state-of-charge to its original position after each 24-hour period the size of the battery can be minimized.

\section{Possible Use of Micro Wind Turbines}

An alternative to solar PV for distributed renewable generation is a micro wind turbine. This option may offer a more cost effective solution for charging systems at locations that have reasonable wind, since the wind blows even at night when the PEV is to be charged and could reduce the required storage size. The output power of a wind turbine is a highly nonlinear function of wind speed. A normalized output power versus wind speed model for micro wind turbines is developed using the averaged output power data of five micro wind turbines from three manufacturers [22]. This normalized output power profile as a function of wind speed, $v_{w}$, is shown in Fig. 8 and approximately modeled by the following expression:

$$
\begin{aligned}
f_{D G, \text { wind }}\left(v_{w}\right)= & 5.808 \times 10^{-2}-1.541 \times 10^{-2} v_{w} \\
& -1.311 \times 10^{-2} v_{w}^{2}+5.883 \times 10^{-3} v_{w}^{3} \\
& -5.131 \times 10^{-4} v_{w}^{4}+1.566 \times 10^{-5} v_{w}^{5} \\
& -1.36 \times 10^{-7} v_{w}^{6} \\
& \quad \text { for } 2.5 \mathrm{~m} / \mathrm{s} \leq v_{w} \leq 20 \mathrm{~m} / \mathrm{s}
\end{aligned}
$$

As in the case of solar PV, $f_{D G \text {,wind }}$ is clipped at its maximum value of 1 , even if (60) gives a higher value. Wind turbines have a cut-in wind speed below which they produce no power. Wind turbines also have a cut-out wind speed beyond which they produce no power in order to protect themselves from damage. In this model, the cut-in wind speed is $2.5 \mathrm{~m} / \mathrm{s}$ and the cut-out wind speed is $20 \mathrm{~m} / \mathrm{s}$. Using this model, the output

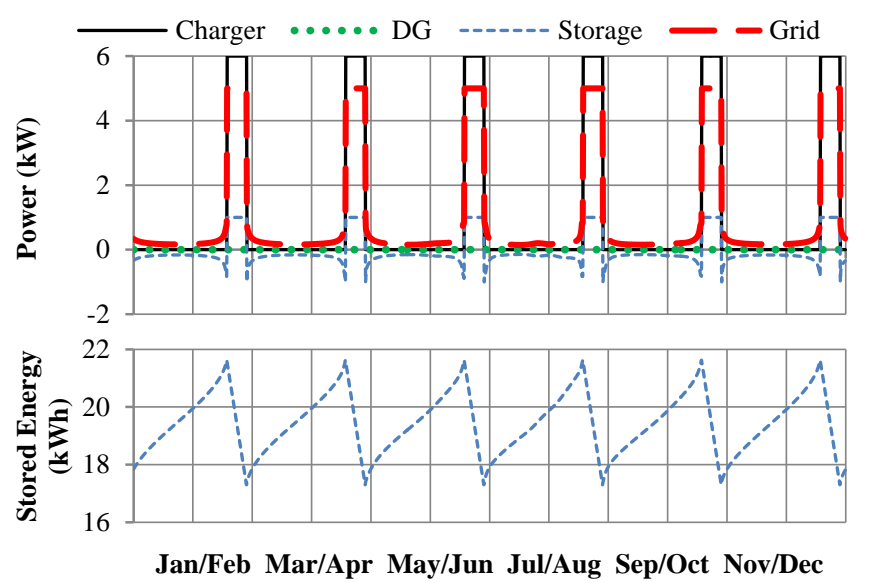

(a)
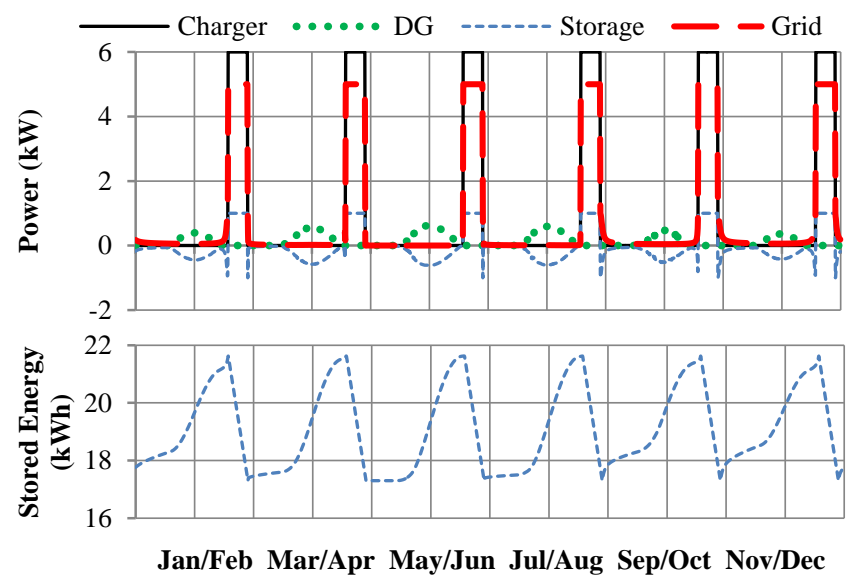

(b)

Fig. 7. Power and energy profiles for the optimal design of a residential PEV charger with integrated solar PV generation and lead-acid storage, assuming the normalized output power profile of (a) Eugene, OR and (b) Los Angeles, CA as depicted in Fig. 6.

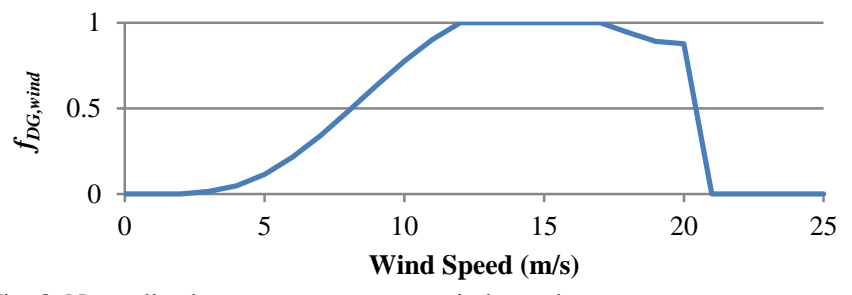

Fig. 8. Normalized output power versus wind speed.

power from micro wind turbines installed in Los Angeles, CA and in Boulder, $\mathrm{CO}$ is calculated and plotted in Fig. 9 using actual wind speed data for 2010-2011 [27], [28]. Fig. 9 shows the high $\left(95^{\text {th }}\right.$ percentile), median $\left(50^{\text {th }}\right.$ percentile), and low $\left(5^{\text {th }}\right.$ percentile) output power profiles for these two locations.

As can be seen from Fig. 9(a), in Los Angeles, even the $95^{\text {th }}$ percentile wind profile utilizes less than $15 \%$ of the rated output power capability of the wind turbine. This is very poor utilization of the renewable DG and leads to optimal designs that do not use a micro wind turbine. Hence solar PV is a better option than micro wind turbines for Los Angeles, CA.

In the case of Boulder, $\mathrm{CO}$, the median output power profile is also quite poor and not favorable for a micro wind turbine in an optimal PEV charging system design. On the other hand, the $95^{\text {th }}$ percentile profile favors a micro wind turbine. These results are summarized in Table IV. 
The power flow for the $95^{\text {th }}$ percentile case is shown in Fig. 10. As seen in Fig. 10, the output of the wind turbine is fairly flat across the day. This means that the storage unit is slowly charged during the day when the PEV is not charging. When the PEV is charging, the wind turbine directly supplies part of its required power. However, it is not reasonable to design the PEV charging system based on the $95^{\text {th }}$ percentile output. Also, the wind data used in this analysis is for a height of 50 meters which may be considered too high for a residential application.

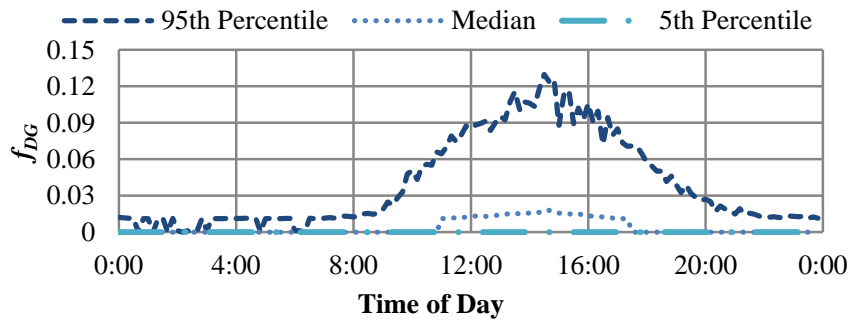

(a)

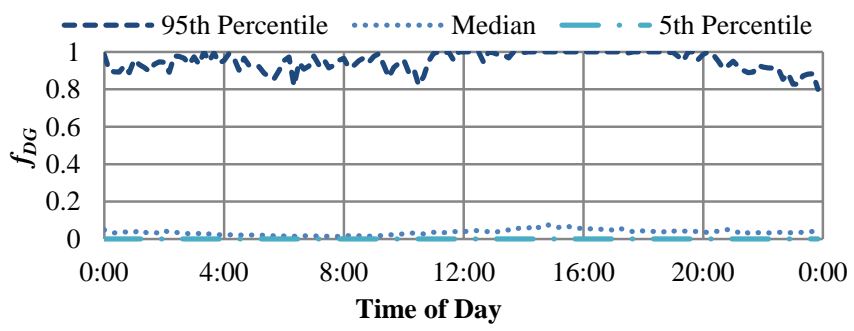

(b)

Fig. 9. Normalized output power profile for micro wind turbine generation at different percentiles of wind speed for (a) Los Angeles, CA [27] and (b) Boulder, CO [28].

TABLE IV

OPTIMAL RATINGS AND LIFECYCLE COSTS FOR DESIGNS WITH WIND TURBINES IN BOULDER, CO

\begin{tabular}{ccrrrrr}
\hline \hline $\begin{array}{c}f_{D G} \\
\text { (percentile) }\end{array}$ & $\begin{array}{c}\mathrm{P}_{\mathrm{DG}, \mathrm{r}} \\
(\mathrm{kW})\end{array}$ & $\begin{array}{c}\mathrm{P}_{\mathrm{S}, \mathrm{r}} \\
(\mathrm{kW})\end{array}$ & $\begin{array}{c}\mathrm{P}_{\mathrm{G}, \mathrm{r}} \\
(\mathrm{kW})\end{array}$ & $\begin{array}{c}\mathrm{E}_{\mathrm{S}, \mathrm{r}} \\
(\mathrm{kWh})\end{array}$ & $\begin{array}{c}\mathrm{E}_{\mathrm{G}, \mathrm{r}} \\
(\mathrm{kWh})\end{array}$ & $\begin{array}{c}\mathrm{C} \\
(\$)\end{array}$ \\
\hline $95^{\text {th }}$ & 0.200 & 0.840 & 5 & 17.62 & 600 & 44,065 \\
$50^{\text {th }}$ & 0 & 1 & 5 & 21.69 & 723 & 47,739 \\
\hline \hline
\end{tabular}
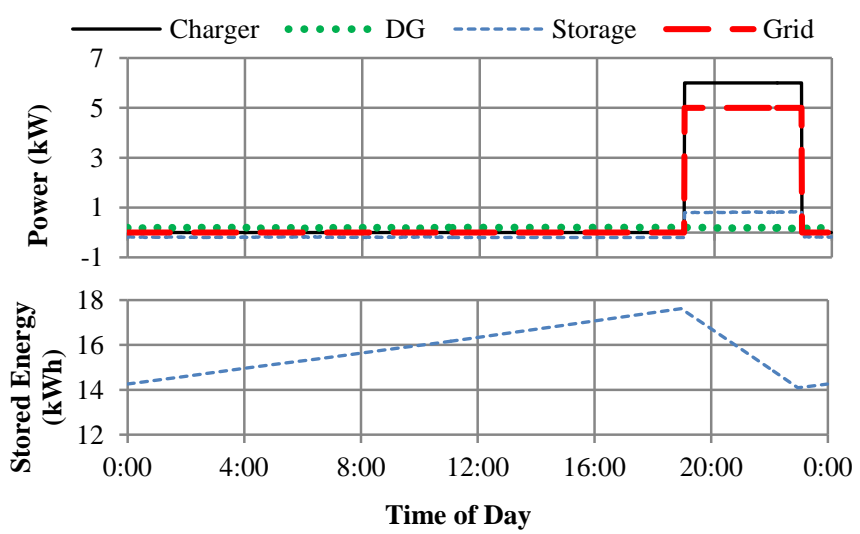

Fig 10. Power and energy profile for the optimal design of a residential PEV charger with integrated wind turbine and lead-acid battery, assuming the $95^{\text {th }}$ percentile normalized output power profile for Boulder, $\mathrm{CO}$ as shown in Fig. 9(b).
Therefore, while wind can be an attractive resource as it can be available at night (or in instances when solar is not an option) and has the potential to reduce the need for storage, the available micro wind technology is not suitable for capturing energy from low wind speeds. It is possible that if the cut-in wind speed was lower and if the wind turbine could reach its rated turbine output power at lower wind speeds, then the utilization factor of micro wind turbines would be much greater. However, with the available technology, residential scale wind turbines are not cost effective for use with PEV chargers at least in locations with wind speeds similar to Los Angeles, CA and Boulder, CO.

\section{Sensitivity Analysis}

The results of the optimization methodology may be sensitive to the assumptions or parameter values. In this section, we explore the sensitivity of the results to an alternate storage technology and its cost, to the time at which the PEV begins to charge, and to the cost of solar PV.

As can be seen from Fig. 5, the cost of storage is a large fraction of the system lifecycle cost. One reason this cost is so high is because the lead-acid batteries have a life of only six years. Hence, in the 20-year life of the system, four lead-acid batteries have to be purchased. Because lead-acid batteries are a very mature technology, major advancements in increasing their life or reducing their cost seem unlikely. On the other hand, Li-ion batteries are a relatively new technology with longer life than lead-acid units and with the potential for significant cost reductions over the next decade [29]. Assuming 12-year life Li-ion batteries, the price, $C$ " $s$, at which Li-ion battery technology becomes cost competitive with lead-acid batteries is investigated.

When the median solar irradiation profile for Los Angeles, $\mathrm{CA}$ is used to find the optimal design for a PEV charging system with a solar PV generation source and a lead-acid battery, the resulting system lifecycle cost is $\$ 46,793$ of which $\$ 20,330$ is the storage cost. The lifecycle cost of systems with Li-ion storage technology depends on the specific cost, $C$ " $S$ (in $\$ / \mathrm{kWh}$ ), of Li-ion batteries. The system lifecycle costs for designs with Li-ion storage technology are plotted as a function of Li-ion specific cost in Fig. 11. Also plotted for reference in Fig. 11 is the lifecycle cost of the system with a lead-acid battery. The breakeven point between Li-ion and lead-acid is marked by a triangle. When the specific cost of Li-ion storage drops below $455 \$ / \mathrm{kWh}, \mathrm{Li}$-ion storage becomes more attractive than lead-acid storage. The current cost of Li-ion batteries is estimated at $800 \$ / \mathrm{kWh}$. However, some industry analysts expect this cost to reduce by $60 \%$ over the

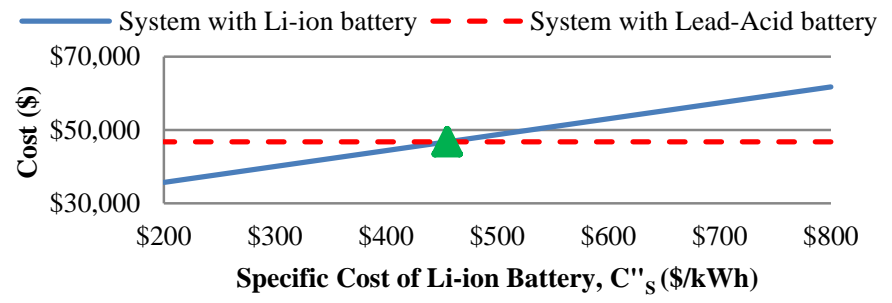


Fig. 11. System lifecycle cost as a function of specific cost of Li-ion batteries. The triangle indicates the specific cost below which $\mathrm{Li}$-ion storage technology is cost competitive with lead-acid storage technology.

next decade [29]. Given these costs, it is quite feasible for $\mathrm{Li}$ ion storage technology to become cost competitive with leadacid storage technology for PEV charging applications over the next decade. However, with the current cost of $\mathrm{Li}$-ion technology, designs with Li-ion batteries result in system lifecycle costs that are roughly $33 \%$ higher than designs with lead-acid batteries.

An area of variability is the time at which the PEV begins to charge. In a charging system that contains a solar PV generator, it may be cost beneficial to charge the PEV when the sun is expected to shine as seen in Fig. 12. When the PEV begins charging around $10 \mathrm{am}$, the solar PV supplies the most power and energy directly to the PEV and reduces the size and cost of the storage unit. For a residential system, it may be difficult to charge the PEV during the day. Charging systems available at work locations may facilitate lower system lifecycle costs. There is negligible cost difference when PEV charging begins sometime between $5 \mathrm{pm}$ and 3 am as seen by the flat cost curve in Fig. 12 for that time range.

One nature of emerging technology is the opportunity for cost reductions over time. In the initial analysis for charging systems located in Eugene, OR, a variable cost of 4,400 $\$ / \mathrm{kW}$ was assumed for the solar PV generator. As the number of installations and suppliers of this technology increases, it is expected that the cost will decrease thereby making solar PV generation a viable alternative to grid energy even in places such as Eugene, OR, whose peak solar irradiation only yields $60 \%$ of rated solar PV output power. It can be seen in Fig. 13 that it is more economical to use solar PV instead of the grid for energy when the cost of solar is low enough even when using the median $\left(50^{\text {th }}\right.$ percentile $)$ solar irradiance profile. Further analysis shows that the variable cost at which it is economical to use solar PV instead of the grid for energy with Eugene, OR's median solar irradiance profile is $3823 \$ / \mathrm{kW}$.

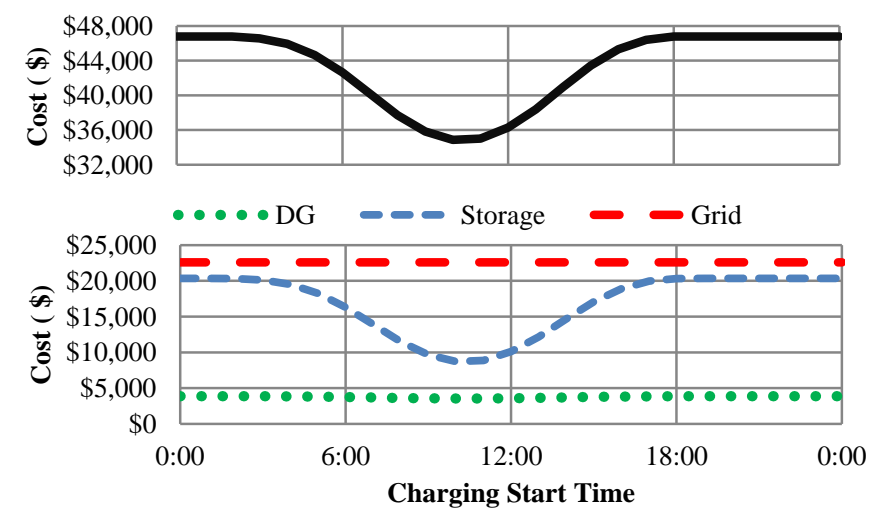

Fig. 12. System lifecycle cost as a function of when the PEV begins to charge. In each case, the PEV charges for 4 hours at a rate of $6 \mathrm{~kW}$.

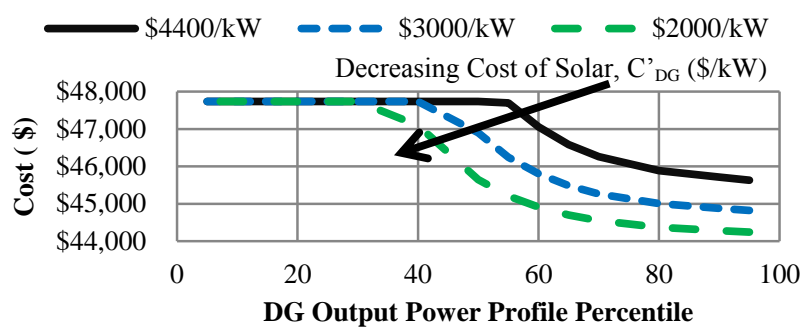

Fig. 13. System lifecycle cost for decreasing variable cost of solar as the solar photovoltaic generation source's normalized output power profile is varied from the $5^{\text {th }}$ percentile to the $95^{\text {th }}$ percentile using Eugene, OR data [26].

\section{CONCLUSIONS AND FUtURE WORK}

In this paper we have presented a framework and methodology for the design of grid-interfaced PEV charging systems that integrate renewable distributed generation and storage. In particular, we develop a linear programming based approach to select designs that minimize system lifecycle cost. We also develop a search-based approach and a mixed integer programming approach to validate these results. We then apply these approaches to a residential charging case in which the peak power drawn by the charger is greater than what can be supplied from the grid. Therefore, the system needs to incorporate a distributed generation source and/or a storage unit.

In our analysis we consider architectures with a lead-acid or Li-ion storage unit and a solar PV-based or a micro wind turbine-based distributed generator for three U.S. locations. Based on the cost and lifetime parameter values used in this analysis, it is shown that designs that draw the maximum available power from the grid have the lowest 20 -year system lifecycle cost. These designs minimize the size of the required storage unit. However, our analysis also shows that on a lifecycle cost basis, designs with a solar PV distributed generator are better than those without one if the median midday irradiation of the location is greater than about 720 $\mathrm{W} / \mathrm{m}^{2}$. This is true because at these locations the additional energy drawn from the grid over the 20 -year period is more expensive than the 20-year lifecycle cost of the solar photovoltaic DG. Additionally, it has been shown that available micro wind turbine technology is not cost effective for PEV chargers at least in locations with wind speeds similar to those of Los Angeles, CA and Boulder, CO. Similarly, Liion storage technology is not yet cost competitive with leadacid storage technology but may become more attractive as its cost decreases over the next decade. Sensitivity analysis has shown that varying the start time of PEV charging between 5 $\mathrm{pm}$ and 3 am has negligible impact to total system lifecycle cost but that shifting to daytime charging, coincident with solar PV output, would decrease the cost substantially. Lastly, as the variable cost of solar decreases, solar PV generators may be attractive in areas with solar irradiation profiles similar to those seen in Eugene, OR.

In the future, the methodology developed here can be extended to evaluate and optimize the design of multiple PEV chargers (such as in a public PEV charging application) that utilize multiple renewable distributed generation sources and/or storage units. 


\section{APPENDIX}

This appendix discusses how the values of some of the parameters listed in Table I and Table II were determined. For further information, see [22].

\section{A. Solar PV Cost Parameter Calculation}

Aggregate industry data suggests that as of August 2011, module costs were $2.84 \$ / \mathrm{W}$ [30]. The aggregate industry data is not broken down into fixed and variable costs. Therefore, price data for BP Solar modules was collected from a number of retail sites and each module price was plotted against the module output power rating [22]. Linear trendlines for each retailer were fitted against the data to calculate the fixed and variable cost components. Using this method, the fixed cost is the intercept of the linear trendline and the variable cost is the slope of the linear trendline. The resulting plot is shown in Fig. 14 and the resulting fixed and variable costs are listed in Table V. The trendlines produce fixed costs between $\$ 55$ and $\$ 165$ and most of variable costs are between 2 \$/W and 2.25 \$/W.

To conduct a similar analysis for the remaining components of a solar PV system such as the inverter, balance of system (BOS), installation, and other/indirect factors, would require data that is not readily available. However, since it has been well-documented that the module cost is roughly $50 \%$ of the total installed cost of a solar PV system, a reasonable estimate can be made using the module cost [31]-[33]. As can be seen from Table $\mathrm{V}$, the fixed cost of the module is roughly $\$ 100$. Doubling this yields a fixed installed cost for solar PV systems (in the power range of interest for residential installations) of $\$ 200$. Also, the variable cost of the module is approximately $2.2 \$ / W$. Hence, the variable cost of the installed solar PV system would be roughly $\$ 4.4 / \mathrm{W}$, or equivalently $4,400 \$ / \mathrm{kW}$ which includes the inverter, BOS, installation and other costs

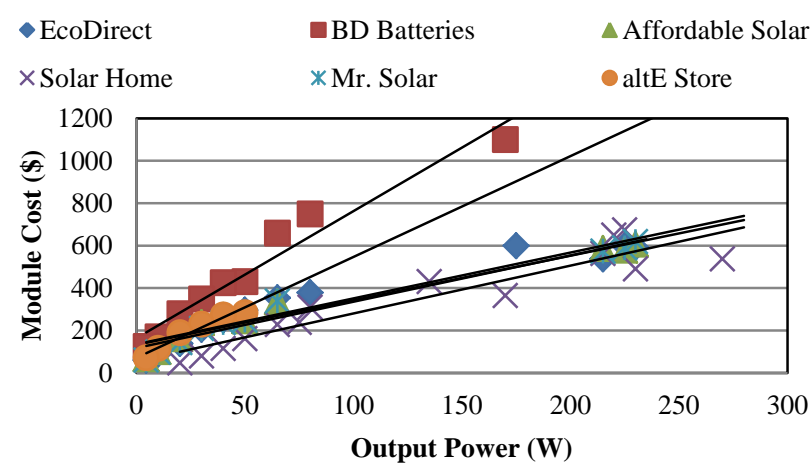

Fig.14. BP Solar module cost and corresponding fitted linear trendlines as a function of module rated output power based on data from six retailers [22].

TABLE V

FIXED AND VARIABLE MODULE COSTS

\begin{tabular}{lccc}
\hline \hline RETAILER & $\begin{array}{c}\text { Fixed Cost } \\
(\$)\end{array}$ & $\begin{array}{c}\text { Variable Cost } \\
(\$ / \mathrm{W})\end{array}$ & $\mathrm{R}^{2}$ Value \\
\hline EcoDirect & 135.65 & 2.1580 & 0.9077 \\
\hline BD Batteries & 164.08 & 5.9836 & 0.9509 \\
\hline Affordable Solar & 132.31 & 2.0993 & 0.9505 \\
\hline Solar Home & 55.194 & 2.2533 & 0.8841 \\
Mr. Solar & 117.59 & 2.1822 & 0.9607 \\
\hline altE Store & 71.707 & 4.7506 & 0.9452 \\
\hline \hline
\end{tabular}

Note: Values based on the linear trendlines in Fig. 14. and is listed in Table I.

\section{B. Storage Unit Life Model}

The life of the storage unit depends on the number of times it has been charged and discharged (also called a cycle). Battery manufacturers may indicate the number of cycles a battery can sustain based upon the depth of discharge (DOD) of the battery such as the data seen in Fig. 15. Depending on the DOD, the amount of energy provided from each cycle is different. However, the energy that is required out of the storage unit is fixed. The rated energy capacity of the storage unit will have to be adjusted to ensure that the required amount of energy is delivered when the DOD is varied.

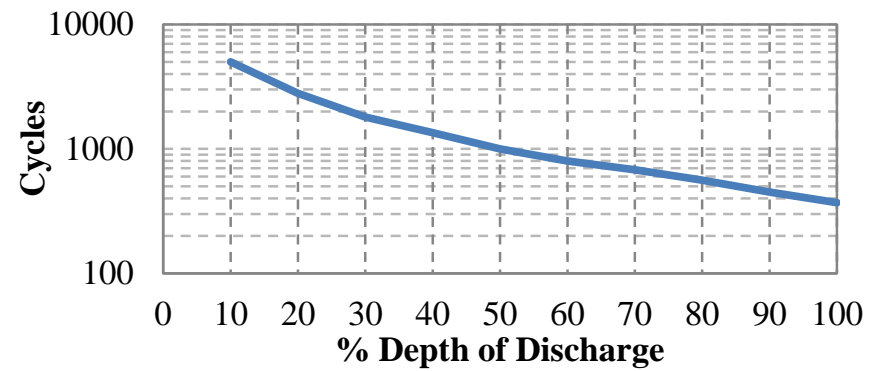

Fig. 15. SunXtender lead-acid expected battery cycle life versus depth of discharge [34].

It was found that the lowest cost occurs when the DOD is limited to $20 \%$ and the battery life is just under 8 years [22]. The $20 \%$ DOD provides a buffer for days when the clouds may cover the sun or the wind may not blow. In these cases, the battery may be safely drained past $20 \%$ DOD. Likewise, over time, it is expected that the battery capacity may decrease to only $80 \%$ of its initial capacity. Toward the end of the battery life, the energy delivered will comprise a higher percentage of the current battery capacity. The battery would be regularly drained past $20 \%$ DOD. For these reasons, the expected life, $T_{\text {life,S }}$, of the lead-acid battery is chosen to be 6 years. For design purposes, to achieve an initial DOD of $20 \%$, the $S O C_{\min }$ is set to 0.80 and the $S O C_{\max }$ is set to 1 as listed in Table II.

\section{ACKNOWLEDGMENT}

The authors wish to acknowledge the guidance and support of Dr. Sindhu Suresh, Yaosuo Xue, Dr. Gerd Griepentrog and John Hurley of Siemens Corporation, Corporate Technology. We would like to recognize the helpful input of Dr. Madhav Manjrekar and Paul Camuti. We also wish to thank Prof. Salal Humair of Harvard University for valuable discussions regarding linear programming, and Ali Afridi of Lexington High School for help with processing the solar irradiation and wind data.

\section{REFERENCES}

[1] M. Duvall and E. Knipping, "Environmental assessment of plug-in hybrid electric vehicles," Electric Power Res. Inst., Palo Alto, CA, Tech. Rep. 1015325, Final Rep., July 2007, vol. 1.

[2] Electrification Coalition, "Electrification roadmap: Revolutionizing transportation and achieving energy security," Washington, DC, Nov. 2009.

[3] Committee on Assessment of Resource Needs for Fuel Cell and Hydrogen Technologies, National Research Council, Transitions to 
Alternative Transportation Technologies - Plug-in Hybrid Electric Vehicles, Washington, DC: The National Academies Press, 2010.

[4] U.S. Energy Information Administration (EIA), "Supplemental tables to the annual energy outlook 2010 with projections to 2035,"U.S. Department of Energy, Washington, DC, Dec. 2009.

[5] S. Powell, Southern California Edison, private communication, Mar. 2010.

[6] SAE Electric Vehicle and Plug in Hybrid Electric Vehicle Conductive Charge Coupler, SAE J1772, Feb. 2012.

[7] J. Motavalli, "Killer app for E.V.'s: 30-minute recharges," The New York Times, Automobiles, pp. 2, Aug. 8, 2010.

[8] J. Barnes (2012, Mar. 6). Renewable portfolio standards update:2012's compliance modifications, progress and prognostications [Online]. Available: http://www.dsireusa.org/documents/PolicyPublications/ Justin_REMA_RPS_Update_March_2012.pptx

[9] P. Richardson, D. Flynn, and A. Keane, "Impact assessment of varying penetrations of electric vehicles on low voltage distribution systems," in Proc. 2010 IEEE Power and Energy Soc. General Meeting, Minneapolis, MN, July 2010.

[10] J. A. P. Lopes, F. J. Soares and P. M. R. Almeida, "Integration of electric vehicles in the electric power system," Proc. IEEE, vol. 99, no.1, pp. 168-183, Jan. 2011.

[11] C. Gerkensmeyer, M. C. W. Kintner-Meyer and J. G. DeSteese, "Technical challenges of plug-in hybrid electric vehicles and impacts to the US power system: distribution system analysis," Pacific Northwest National Lab., Tech Rep. PNNL-19165, Jan. 2010.

[12] P. P. Barker and R. W. De Mello, "Determining the impact of distributed generation on power systems: Part I - Radial distribution systems," in Proc. IEEE Power Eng. Soc. Summer Meeting, vol. 3, pp. 1645-1656, 2000.

[13] E. Wesoff, "Envision's solar PV building in a box," Greentech Media, Oct. 1, 2010.

[14] A. Smith and G. Gill, Toward Zero Carbon: The Chicago Central Area DeCarbonization Plan, Mulgrave, Victoria, Australia: The Images Publishing Group Pty Ltd, 2011, ch. 3, sec. 8, pp. 218-219.

[15] E. Wesoff, "Solar Frontier CIS PV panels charging the Nissan Leaf," Greentech Media, July 11, 2011.

[16] N. Halverson, "Electric vehicle charger powered by wind and solar," Discovery News, July 28, 2011.

[17] D. Xu, L. Kang, L. Chang, and B. Cao, "Optimal sizing of standalone hybrid wind/PV power systems using genetic algorithms," in Proc. Canadian Conf. on Electr. and Computer Eng., Saskatoon, SK, Canada, May 2005, pp. 1722-1725.

[18] B. S. Borowy and Z. M. Salameh, "Methodology for optimally sizing the combination of a battery bank and PV array in a wind/PV hybrid system," IEEE Trans. on Energy Convers., vol. 11, no. 2, pp. 367-375, June 1996.

[19] A. Gupta, R. P. Saini, and M. P. Sharma, "Hybrid energy system sizing incorporating battery storage: An analysis via simulation calculation," in Proc. 2009 3rd Int. Conf. on Power Syst., Kharagpur, India, Dec. 2009.

[20] IEEE Recommended Practice for Sizing Lead-Acid Batteries for StandAlone Photovoltaic (PV) Systems, IEEE Standard 1013, 2007.

[21] S. J. Gunter, K. K. Afridi, and D. J. Perreault, "Optimal design of gridinterfaced EV chargers with integrated generation," in Proc. IEEE PES Innovative Smart Grid Technologies (ISGT) Conf., Jan. 16-20, 2012.

[22] S. J. Gunter, "Methodology for combined integration of electric vehicles and distributed resources into the electric grid," M.S. thesis, Dept. Elect. Eng. and Comput. Sci., Massachusetts Inst. of Technol., Cambridge, MA, 2011.

[23] D. Bertsimas and J. N. Tsitsiklis, Introduction to Linear Optimization, Belmont, MA: Athena Scientific, 1997.

[24] ECOtality, Inc., "The EV project quarterly report: Fourth quarter 2011," Feb. 2012.

[25] J. LeBrun, DTE Energy, "Plug-in electric vehicle overview," presentation at A Tale of Three Cities, webcast hosted by Intelligent Utility, Jan. 2011.

[26] University of Oregon Solar Radiation Monitoring Laboratory (2011, June 21). Solar data [Online]. Available: http://solardat.uoregon.edu/ SolarData.html

[27] National Renewable Energy Laboratory (2011, July 11). Solar resource \& meteorological assessment project (SOLRMAP): Loyola Marymount University [Online]. Available: http://www.nrel.gov/midc/lmu/

[28] National Renewable Energy Laboratory (2011, June 30). Solar resource \& meteorological assessment project (SOLRMAP): National Wind
Technology Center [Online]. Available at: http://www.nrel.gov/mide/ nwtc_m2/

[29] P. Sankey, D. T. Clark, and S. Micheloto, "The end of the oil age - 2011 and beyond: a reality check," Deutsche Bank Securities Inc., Dec. 2010.

[30] The NPD Group (2011, Aug. 8) Solarbuzz: Solar market research and analysis [Online]. Available: http://www.solarbuzz.com/

[31] R. A. Sutula, "Solar energy technologies program multi-year program plan, 2007-2011," U.S. Dept. of Energy, Washington, DC, Jan. 2006.

[32] S. Price and R. Margolis, "2008 solar technologies market report," U.S. Dept. of Energy, Washington, DC, Jan. 2010.

[33] L. Bony, S. Doig, C. Hart, E. Maurer, and S. Newman, "Achieving lowcost solar PV: Industry workshop recommendations for near-term balance of system cost reductions," Rocky Mountain Inst., Snowmass, CO, Sep. 2010.

[34] Technical Manual for Sun Xtender Batteries, Concorde Battery Corp., West Covina, CA, 2011, pp. 40.

\section{BIOGRAPHIES}

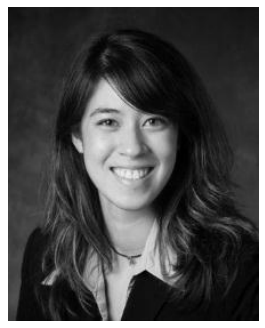

Samantha J. Gunter (S'10) received the B.S. degree in electrical engineering from the University of Illinois at Urbana-Champaign in 2009 and the S.M degree in electrical engineering and computer science from the Massachusetts Institute of Technology (MIT) in 2011. She is currently pursuing a $\mathrm{PhD}$ degree in electrical engineering at MIT. Her professional experience includes power and energy related internships at International Truck and Engine Corporation, General Electric, and the Army Corps of Engineers. She has been awarded the Paul R. Egbert Memorial Award, the Grainger Award, the CEME Research and Leadership Award, and a MITEI research fellowship for her work and interest in power and energy systems.

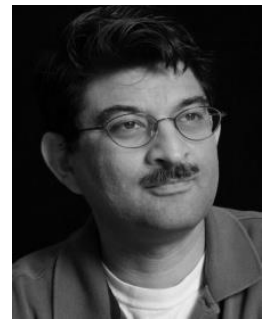

Khurram K. Afridi (S'93-M'98) received the B.S. degree in electrical engineering from the California Institute of Technology (Caltech) in 1989 and the S.M. and Ph.D. degrees in electrical engineering and computer science from the Massachusetts Institute of Technology (MIT) in 1992 and 1998, respectively. Between degrees he worked for JPL, Lutron, Philips, and Schlumberger. In 1997, he joined the founding team of Techlogix as Chief Technology Officer and became Chief Operating Officer in 2000. From 2004 to 2008 he also led the development of LUMS School of Science and Engineering (SSE) as Project Director, and was appointed Associate Professor and the Werner-von-Siemens Chair for Power Electronics in 2008. Since 2009 he is at MIT as a Visiting Associate Professor in the Department of Electrical Engineering and Computer Science. His research interests are in power electronics and energy systems. Dr. Afridi received the Carnation Merit Award from Caltech and the BMW Scientific Award from BMW AG.

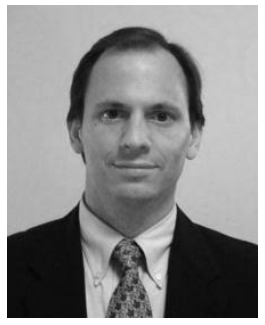

David J. Perreault (S'91-M'97-SM'06-F'13) received the B.S. degree from Boston University, Boston, MA, in 1989, and the S.M. and Ph.D. degrees from the Massachusetts Institute of Technology (MIT), Cambridge, MA, in 1991 and 1997, respectively. In 1997, he joined the Laboratory for Electromagnetic and Electronic Systems, MIT as a Postdoctoral Associate, and became a Research Scientist in 1999. In 2001, he joined the Department of Electrical Engineering and Computer Science, MIT, where he is currently a Professor. He has coauthored four IEEE prize papers. His research interests include design, manufacturing, and control techniques for power electronics, and their use in a wide range of applications. Dr. Perreault received the Richard M. Bass Outstanding Young Power Electronics Engineer Award from the IEEE Power Electronics Society, an Office of Naval Research Young Investigator Award, and the Society of Automotive Engineers Ralph R. Teetor Educational Award. 